\title{
Buoyancy-aided Conjugate Mixed Convection with Surface Radiation from an Electronic Board with Non-Identical Heating
}

\author{
G. Ganesh Kumar ${ }^{1, *}$, C. Gururaja Rao ${ }^{2}$ \\ ${ }^{1}$ Department of Mechanical Engineering, Kakatiya Institute of Technology and Science, India \\ ${ }^{2}$ Department of Mechanical Engineering, National Institute of Technology, India
}

Copyright (C) 2013 Horizon Research Publishing All rights reserved.

\begin{abstract}
A numerical probe into buoyancy - aided conjugate mixed convection with surface radiation from a discretely and non-identically heated vertical electronic Board is investigated here. The board considered contains three discrete heat sources of progressively decreasing heights flush-mounted in it from the leading edge to the trailing edge. The left, right, top and non-heat source portions of the board were assumed to be adiabatic, while the heat generated in the three heat sources is conducted only along the heat source portions of the plate, before getting dissipated from there by mixed convection and radiation. Air which is of constant physical properties is considered as a cooling medium. The fluid flow and heat transfer equations are considered without boundary layer approximations. These equations are solved using finite volume formulation along with Gauss-Seidel solver. Certain parametric studies are made and the prominent of them are presented here.
\end{abstract}

Keywords Conjugate Mixed Convection, Surface Radiation, Buoyancy, Interaction, Electronic Board

\section{Introduction}

A probe into the literature on multi-mode heat transfer provides a large number of analytical, numerical, empirical and semi-empirical works concerning various geometries. A few of these studies are highlighted here. Tewari and Jaluria (1990) conducted an experimental investigation on conjugate mixed convection from a flat plate provided with two heat sources of finite width and negligible thickness. They considered both horizontal and vertical orientations of the plate in their study. Kishinami et al. (1995) performed numerical as well as experimental studies on laminar mixed convection from a vertical composite plate comprising isolated, discontinuous surface heating elements.

A numerical examination of the effect of surface radiation on mixed convection involving viscous incompressible fluid flow past a heated vertical flat plate for the cases of uniform free stream and uniform surface temperatures has been performed by Hossain and Takhar (1996). An analytical and experimental solution to the problem of conjugate laminar as well as turbulent natural convection from a vertical plate is reported by Kimura et. al., (1998). The problem of two-dimensional steady incompressible laminar mixed convection with radiation from a vertical plate with solitary discrete heat source flush-mounted in it has been numerically solved by Gururaja Rao et. al.(2001). The uniqueness of their work is that they considered the pertinent fluid flow and energy equations in their full strength without the usually made boundary layer approximations. Extending this problem, Gururaja Rao (2004) examined the effect of traversing the heat source (changing position) along the plate. He considered as many as thirteen positions for the heat source from the leading to the trailing edge of the plate. Chen et. al., (2006) performed an experimental investigation into natural convection heat transfer coupled with internal conduction from a discretely heated steel plate equipped with nine horizontal heat strip heaters on its back surface. Sawant and Gururaja Rao (2010) studied, numerically, the problem of conjugate mixed convection with radiation from a vertical plate with uniform internal heat generation.

A review of the above summarized literature indicates that exhaustive studies on a vertical plate with multiple non-identical discrete heat sources and with (i) heat dissipating and (ii) adiabatic non-heat source portions are not available. In view of the above, the present paper takes up detailed parametric studies on conjugate mixed convection with radiation from a non-identically and discretely heated vertical plate. Both the possibilities of (i) heat dissipating and (ii) adiabatic non-heat source portions are considered. 


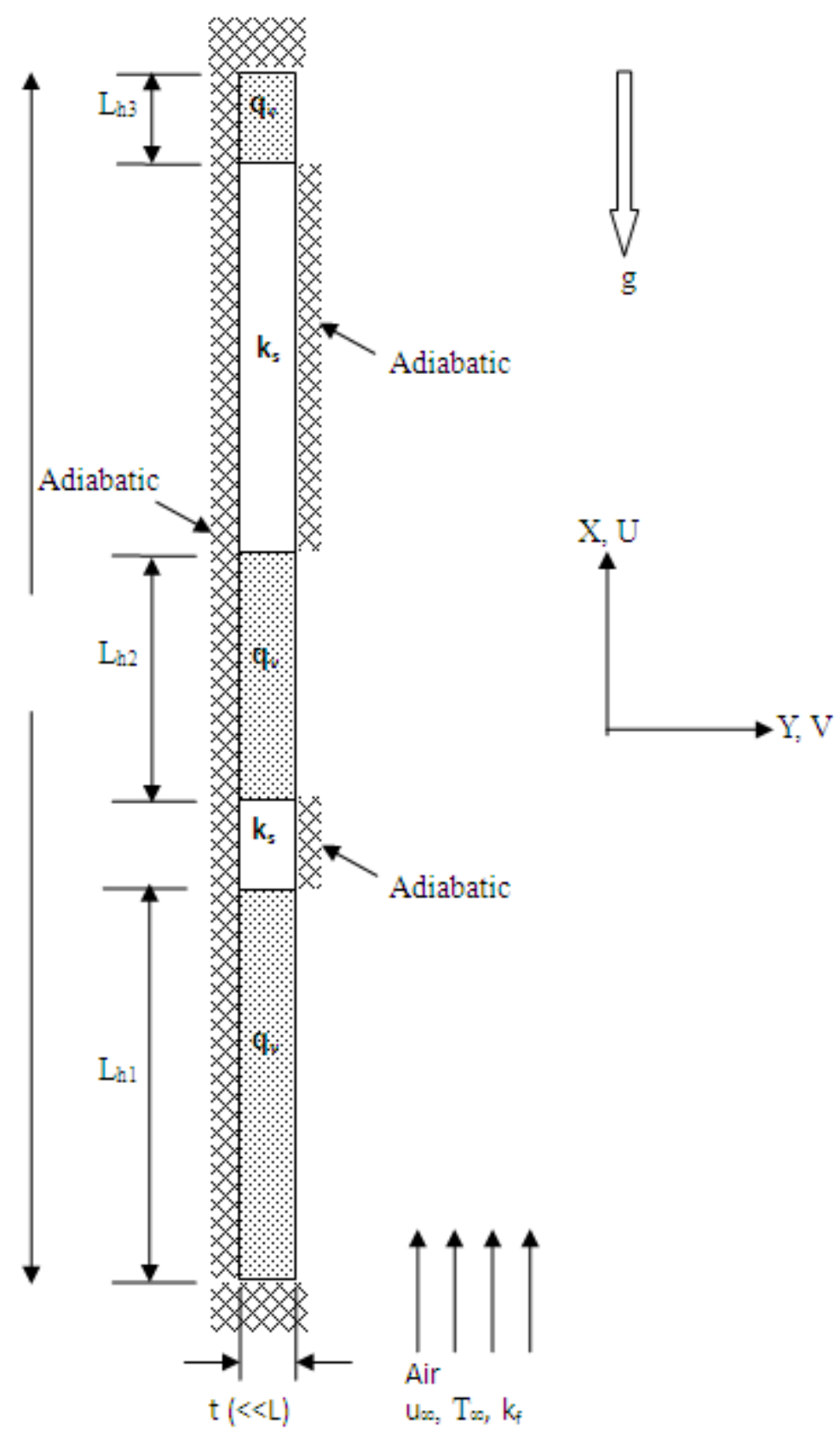

Figure 1. Schematic of Vertical plate with three non-identical discrete heat sources with adiabatic non-heat source portions considered for study

\section{Research Methodology}

The problem geometry chosen for the present study is a vertical board consisting of three non-identical flush-mounted discrete heat sources arranged in a descending order of their heights along its length from the leading edge to the trailing edge. The vertical board is of height $\mathrm{L}$ and thickness $\mathrm{t}(<<\mathrm{L})$. The heights of the three non-identical discrete heat sources as considered from the leading edge are, respectively, $\mathrm{L}_{\mathrm{h} 1}, \mathrm{~L}_{\mathrm{h} 2}$, and $\mathrm{L}_{\mathrm{h} 3}\left(\mathrm{~L}_{\mathrm{h} 1}>\mathrm{L}_{\mathrm{h} 2}>\right.$ $\mathrm{L}_{\mathrm{h} 3}$ ). As obvious from the figure, all the heat sources are of identical thickness $t$. The heat sources have identical rate of volumetric heat generation $\mathrm{q}_{\mathrm{v}}$. However, owing to the difference in their heights, the net rate of heat generation is non-identical in the three heat sources. The system of coordinates considered is also shown in the Fig.1.

The cooling medium (air) is assumed to be of constant thermo physical properties with the Boussinesq approximation considered valid. Further, air is considered to be transparent to thermal radiation. The top, left and bottom surfaces of the board are assumed adiabatic. Further, the right surfaces of the non-heat source portions of the board too are treated to be adiabatic. Thus, the heat generated in the three heat sources is conducted axially (X-direction) along the board and is later dissipated into air by mixed convection and radiation from the right surfaces of the three heat sources. The free stream velocity and temperature of air are $\mathrm{u}_{\infty}$ and $\mathrm{T}_{\infty}$, respectively. The thermal conductivity of the plate as well as heat sources is $\mathrm{k}_{\mathrm{s}}$, while $\varepsilon$ is the surface emissivity of the plate. 
The governing equations for fluid flow and heat transfer are continuity equation, $\mathrm{x}$ and $\mathrm{y}$ momentum equations and equation of energy, which are as follows:

$$
\begin{gathered}
\frac{\partial u}{\partial x}+\frac{\partial v}{\partial y}=0 \\
u \frac{\partial u}{\partial x}+v \frac{\partial u}{\partial y}=-\frac{1}{\rho} \frac{\partial P}{\partial x}+\left(g \frac{\rho_{\infty}}{\rho}-g\right)+v\left[\frac{\partial^{2} u}{\partial x^{2}}+\frac{\partial^{2} u}{\partial y^{2}}\right] \\
u \frac{\partial v}{\partial x}+v \frac{\partial v}{\partial y}=-\frac{1}{\rho} \frac{\partial P}{\partial y}+v\left[\frac{\partial^{2} v}{\partial x^{2}}+\frac{\partial^{2} v}{\partial y^{2}}\right] \\
u \frac{\partial T}{\partial x}+v \frac{\partial T}{\partial y}=\alpha\left[\frac{\partial^{2} T}{\partial x^{2}}+\frac{\partial^{2} T}{\partial y^{2}}\right]
\end{gathered}
$$

These equations are converted into stream function-vorticity formulation and non-dimensionalized using the appropriate normalizing parameters.

An extended computational domain (height $=2 \mathrm{~L}$ and width $=\mathrm{L}$ ) is considered for solving the above equations. These dimensions of the computational domain are decided based on some initial studies made on a pure mixed convection problem concerning the vertical plate geometry. The computational domain is discretized by using semi-cosine grids in horizontal direction and uniform grids of varying fineness in the axial direction. Semi-cosine grids are chosen across the plate to cater to steep velocity and temperature gradients nearer to the plate.

The discretization of computational domain is made based on a detailed grid sensitivity test carried out in three phases. The study is made for a fixed input of $\mathrm{q}_{\mathrm{v}}=10^{6}$ $\mathrm{W} / \mathrm{m}^{3}, \mathrm{k}_{\mathrm{s}}=0.25 \mathrm{~W} / \mathrm{m} \mathrm{K}, \varepsilon=0.45, \mathrm{Ri}_{\mathrm{L}}{ }^{*}=1$. The results of the study has obtained as $\mathrm{M}=171, \mathrm{M}_{1}=51, \mathrm{M}_{2}=61 \mathrm{M}_{3}=$ $101, M_{4}=121, M_{5}=151$, and $N=121$. The same grid size was used for the following studies.

\section{Results and Discussion}

The nature of variation of the local plate temperature [T(x)] with surface emissivity for a given fixed input of $\mathrm{q}_{\mathrm{v}}=10^{6}$ $\mathrm{W} / \mathrm{m}^{3}, \mathrm{k}_{\mathrm{s}}=0.25 \mathrm{~W} / \mathrm{m} \mathrm{K}, \mathrm{Ri}_{\mathrm{L}}{ }^{*}=250$ is shown in Fig.2. For a given surface emissivity $(\varepsilon)$, the plate temperature increases sharply upto the top end of the bottommost discrete heat source. In the subsequent non-heat source portion of the plate, which is adiabatic, the temperature undergoes a mild increase. Again, in the second heat source portion, the temperature undergoes a sharper increase, before again becoming almost asymptotic in the second adiabatic non-heat source portion that follows. The temperature once again, rises sharply in the third heat source and reaches a peak just a head of the adiabatic top end of the plate. A small kink noticed at the trailing edge of the plate is attributed to the change in the temperature boundary conditions along the extended domain. A similar trend is noticed with all the three values of $\varepsilon$ chosen. However, as can be seen, there is an appreciable drop in the local temperature with increase in $\varepsilon$ for a given set of input parameters. This is on account of rise in radiative heat dissipation with increasing $\varepsilon$. In the present example, the temperature at the geometric centre of the plate is dropping down by $27.50 \%$ as $\varepsilon$ increases from 0.05 to 0.45 , while a further rise in $\varepsilon$ to 0.85 , is bringing down $\mathrm{T}(\mathrm{x})$ by $19.34 \%$. It may further be noticed that there is a more pronounced drop in $\mathrm{T}(\mathrm{x})$ between $\varepsilon=0.05$ and 0.45 than that between $\varepsilon=0.45$ and 0.85

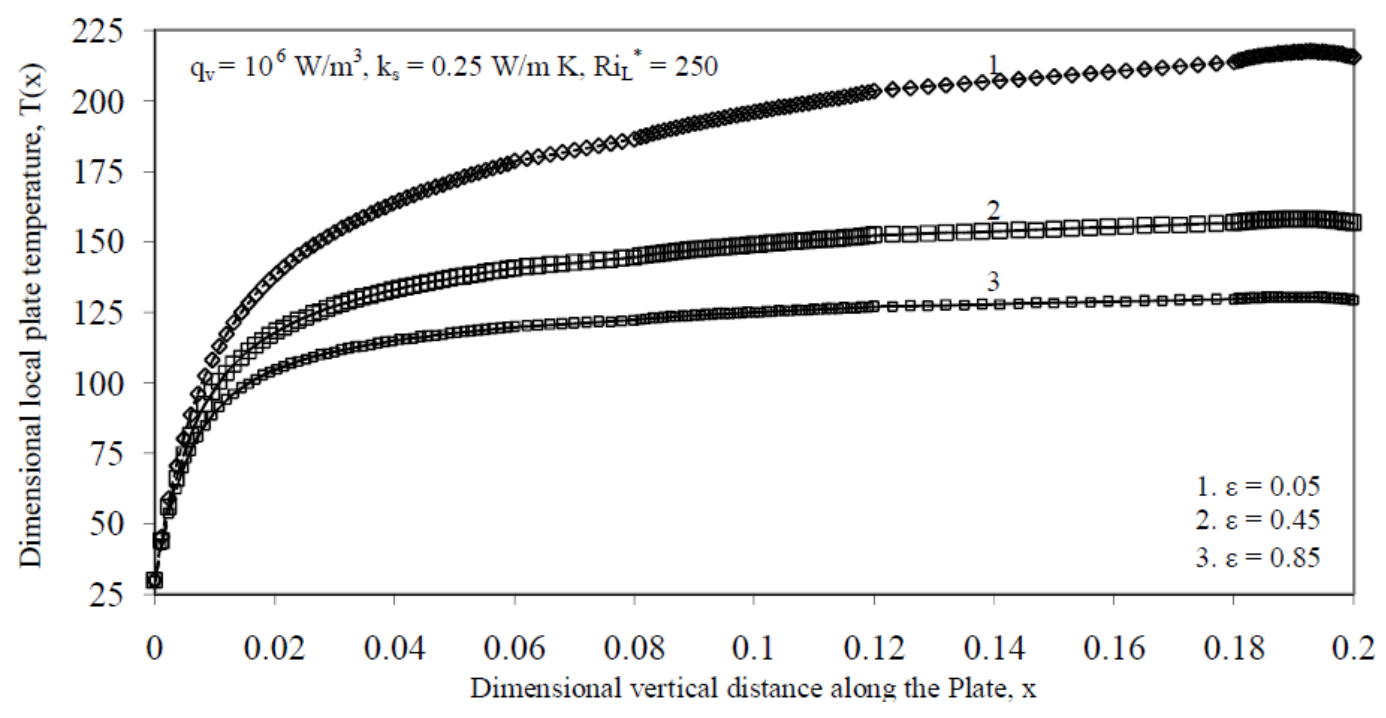

Figure 2. Local plate temperature profiles for different emissivities of the surface of the plate. 


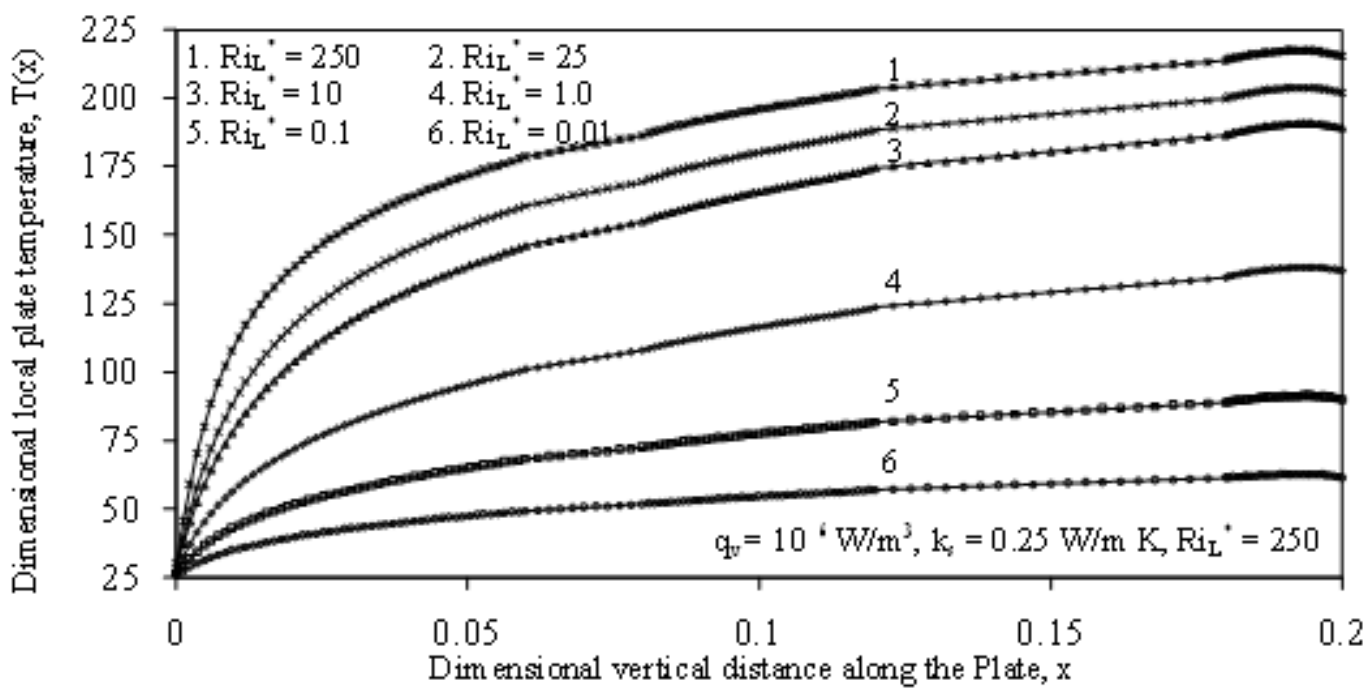

Figure 3. Local plate temperature profiles in different regimes of mixed convection.

Figure 3 shows variation of local non-dimensional plate temperature in various regimes of mixed convection with other parameters held fixed. Six values of modified Richardson number $\left(\mathrm{Ri}_{\mathrm{L}}{ }^{*}\right)$ are chosen in the range $0.01 \leq \mathrm{Ri}_{\mathrm{L}}{ }^{*}$ $\leq 250$. As mentioned already, the upper limit of $\mathrm{Ri}_{\mathrm{L}}{ }^{*}$ indicates the asymptotic free convection limit, while the lower limit of $\mathrm{Ri}_{\mathrm{L}}{ }^{*}$ signifies the asymptotic forced convection limit. For a given $\mathrm{Ri}_{\mathrm{L}}{ }^{*}$, the trend taken by $\theta(\mathrm{X})$ is identical to what has been noticed with reference to Fig 5.3. However, as the flow transits from free convection dominance to forced convection dominance, there is a large drop in $\theta(X)$ owing to increased role played by inertial forces in comparison to buoyancy forces. In the present case, the peak plate temperature, for example, is dropping down by a huge $80.37 \%$ as $\mathrm{Ri}_{\mathrm{L}}{ }^{*}$ decreases from 250 to 0.01 .

The nature of variation of the maximum plate temperature $\left(\mathrm{T}_{\max }\right)$ with surface emissivity $(\varepsilon)$ in various regimes of mixed convection is depicted in Fig.4 Four different values of modified Richardson number $\left(\mathrm{Ri}_{\mathrm{L}}{ }^{*}\right)$ are considered, while $\varepsilon$ is varied between 0.05 and 0.85 , as shown. The fixed input for the study is $\mathrm{q}_{\mathrm{v}}=10^{6} \mathrm{~W} / \mathrm{m}^{3}$ and $\mathrm{k}_{\mathrm{s}}=1 \mathrm{~W} / \mathrm{m} \mathrm{K}$. Surface emissivity shows a significant effect on maximum temperature for $\mathrm{Ri}_{\mathrm{L}}{ }^{*}=25$, which indicates the asymptotic free convection dominant regime. Here, as $\varepsilon$ increases from 0.05 to $0.85, \mathrm{~T}_{\max }$ is decreasing quite largely (by $43.3 \%$ ). A similar trend could be seen with $\mathrm{Ri}_{\mathrm{L}}{ }^{*}=10$ as well. As there is a transition in flow regime from free convection limit to forced convection limit, the role of emissivity in controlling $\mathrm{T}_{\max }$ progressively decreases. This is on account of the increasing dominance of convection over radiation for this kind of larger values of $\mathrm{Ri}_{\mathrm{L}}{ }^{*}$. As an example, for $\mathrm{Ri}_{\mathrm{L}}{ }^{*}=1$ (pure mixed convection), $\mathrm{T}_{\max }$ decreases by $31.25 \%$, with $\mathrm{Ri}_{\mathrm{L}}{ }^{*}=0.1$ bringing down the drop in $\mathrm{T}_{\max }$ between the same limiting values of $\varepsilon$ to just $19.44 \%$. The figure also shows that, for a given surface coating of the plate, $\mathrm{T}_{\max }$ decreases significantly on decreasing $\mathrm{Ri}_{\mathrm{L}}{ }^{*}$. The above is due to the expected increase in the impressed flow velocity for other fixed values of input parameters. For $\varepsilon=0.45, \mathrm{~T}_{\max }$ is dropping down by as much as $53.34 \%$ as the flow regime transits from the asymptotic free to forced convection limit.

Figure 5 shows the study performed on the role of buoyancy in different regimes of mixed convection $(0.01 \leq$ $\mathrm{Ri}_{\mathrm{L}}{ }^{*} \leq 250$ ). The fixed input of $\mathrm{q}_{\mathrm{v}}, \mathrm{k}_{\mathrm{s}}$ and $\varepsilon$ is as shown in figure that shows the maximum plate temperature $\left(\theta_{\max }\right)$ plotted against the modified Richardson number. Curve 1 belongs to the case, where both free and forced convection effects are considered, while the buoyancy term is artificially suppressed in curve 2 . It can be clearly seen that the contribution from free convection is not very significant in forced convection dominant regime where as in free convection dominant regime the effect of buoyancy is quite large and it increases towards larger values of $\mathrm{Ri}_{\mathrm{L}}{ }^{*}$. In the present example, for $\mathrm{Ri}_{\mathrm{L}}{ }^{*}=0.01$ (asymptotic forced convection limit), there is not much to choose between curves 1 and 2 as $\theta_{\max }$ increases just by $0.005 \%$ when buoyancy is ignored. Likewise, for $\mathrm{Ri}_{\mathrm{L}}{ }^{*}=1, \theta_{\max }$ increases by $1.75 \%$, and for $\mathrm{Ri}_{\mathrm{L}}{ }^{*}=10$, the increase in $\theta_{\max }$ is by $14.27 \%$. For the asymptotic free convection limit $\left(\mathrm{Ri}_{\mathrm{L}}{ }^{*}=\right.$ $250), \theta_{\max }$ increases by as much as $43.78 \%$, when the role of buoyancy is ignored and only forced convection is accounted for.

\section{Concluding Remarks}

A numerical investigation into the effect of surface radiation on combined conduction and mixed convection from a discretely and non-identically heated vertical electronic board is made. A few of the prominent results obtained using the computer code specifically written for the purpose are presented. The influence of various parameters effecting the fluid flow and heat transfer results of the present fan-driven mixed convection problem is clearly elucidated. 


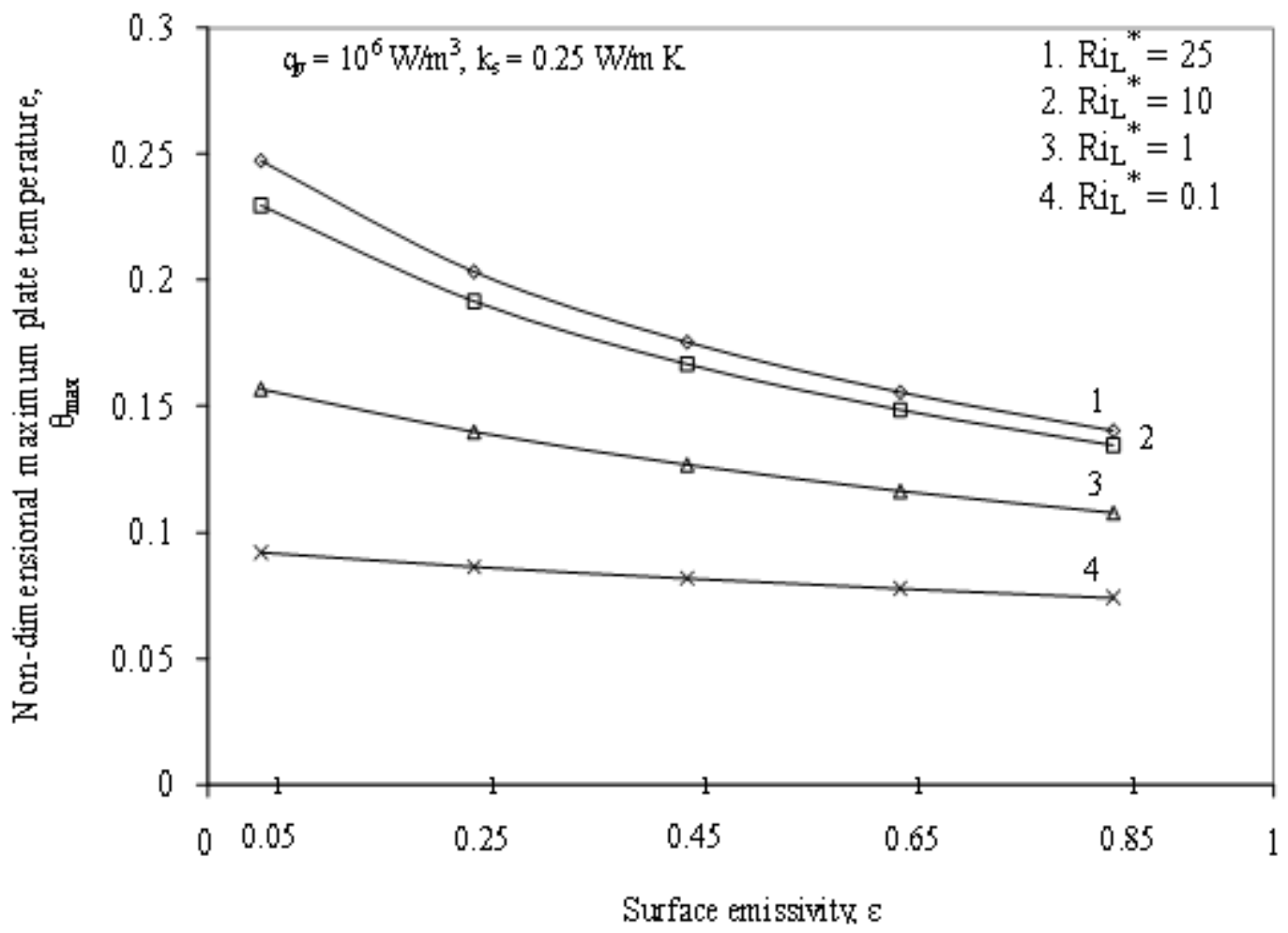

Figure 4. Variation of non-dimensional maximum plate temperature with surface emissivity in different regimes of mixed convection.

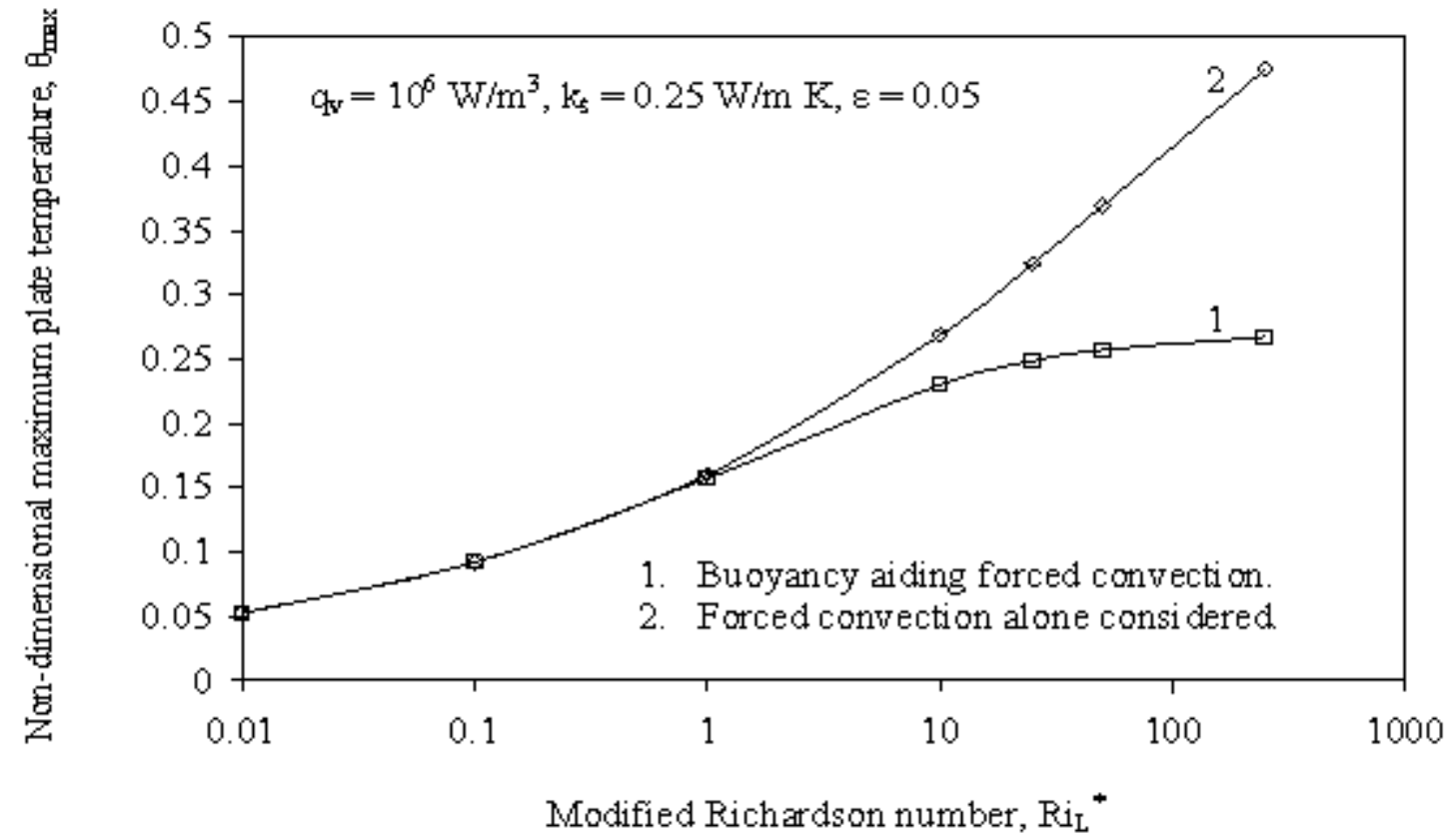

Figure 5. Comparison of non-dimensional maximum plate temperature in different regimes of convection with and without buoyancy taken into account. 


\section{Nomenclature}

$\mathrm{k}_{\mathrm{f}} \quad$ thermal conductivity of air, W/m K

$\mathrm{k}_{\mathrm{s}} \quad$ thermal conductivity of plate material and heat source, $\mathrm{W} / \mathrm{m} \mathrm{K}$

$\mathrm{L}, \mathrm{L}_{\mathrm{h}}, \mathrm{t}$ heights of plate and heat source and thickness of both, respectively, $\mathrm{m}$

$\mathrm{L}_{\mathrm{h} 1}, \mathrm{~L}_{\mathrm{h} 2}, \mathrm{~L}_{\mathrm{h} 3}$ heights of heat source 1 , heat source 2 and heat source 3 , respectively, $m$

$\mathrm{M}, \mathrm{N} \quad$ total number of grids in $\mathrm{X}$ and $\mathrm{Y}$ directions, respectively

$\mathrm{M}_{1} \quad$ grid number at the top end of the first heat source in the plate

$\mathrm{M}_{2} \quad$ grid number at the bottom end of the second heat source in the plate

$\mathrm{M}_{3} \quad$ grid number at the top end of the second heat source in the plate

$\mathrm{M}_{4} \quad$ grid number at the bottom end of the third heat source in the plate

$\mathrm{M}_{5} \quad$ total number of grids along the plate

$\mathrm{Pe}_{\mathrm{L}} \quad$ Peclet number, $\operatorname{Re}_{\mathrm{L}} \operatorname{Pr}$ or $\mathrm{u}_{\infty} \mathrm{L} / \alpha$

Pr Prandtl number

$\mathrm{q}_{\mathrm{v}} \quad$ rate of volumetric heat generation in each discrete heat source, $\mathrm{W} / \mathrm{m}^{3}$

$\operatorname{Re}_{\mathrm{L}} \quad$ Reynolds number, $\left[\left(\mathrm{u}_{\infty} \mathrm{L}\right) / \mathrm{v}_{\mathrm{f}}\right]$

$\mathrm{Ri}_{\mathrm{L}}{ }^{*} \quad$ modified Richardson number, [ $\left(\mathrm{g} \beta \Delta \mathrm{T}_{\mathrm{ref}}\right.$ L) $\left./ \mathrm{u}_{\infty}{ }^{2}\right]$

$\mathrm{t} \quad$ thickness of the plate, $\mathrm{m}$

$\mathrm{T}$ local temperature in the computational domain, $\mathrm{K}$ or ${ }^{\circ} \mathrm{C}$

$\mathrm{T}_{\infty} \quad$ free stream temperature of air, $\mathrm{K}$ or ${ }^{\circ} \mathrm{C}$

$\mathrm{T}_{\max } \quad$ maximum temperature in the computational domain, $\mathrm{K}$ or ${ }^{\circ} \mathrm{C}$

$\mathrm{U}$ non-dimensional vertical velocity of air, $\mathrm{u} / \mathrm{u}_{\infty}$ or $(\partial \psi / \partial \mathrm{Y})$

$\mathrm{V}$ non-dimensional horizontal velocity of air, $\mathrm{v} / \mathrm{u}_{\infty}$ or $(-\partial \psi / \partial \mathrm{X})$

$\alpha$

thermal diffusivity, $\left(\mathrm{k} / \rho \mathrm{c}_{\mathrm{p}}\right)$

\section{Subscripts}

conduction, $\mathrm{x}$, in conduction, $\mathrm{x}$, out

convection

radiation conduction heat transfer out of an element along the plate

convection heat transfer from an element of the plate

radiation heat transfer from an element of the plate

\section{REFERENCES}

[1] Sawant S. M., and Gururaja Rao C. (2010) Combined conduction-mixed convection -surface radiation from a uniformly heated vertical plate. Chemical Engineering Communications, 7, 1-19

[2] Gururaja Rao, C. (2004) Buoyancy-aided mixed convection with conduction and surface radiation from a vertical electronic board with a traversable discrete heat source, Numerical Heat Transfer, Part A: Applications, 45, 935-956

[3] Chen, L. H., Tian, H. Z., and Zhang, D. B. (2006) Experimental study on natural convective heat transfer from a vertical plate with discrete heat sources mounted on the back, Energy Conversion and Management, 47, 3447-3455

[4] Gururaja Rao, C., Balaji. C., and Venkateshan, S. P. (2001) Conjugate mixed convection with surface from a vertical plate with a discrete heat source, ASME Journal of Heat Transfer, 123, 698-702.

[5] Kimura, S., Okajima, A., and Kiwata T. (1998) Conjugate natural convection from a vertical heated slab, International Journal of Heat and Mass Transfer, 41, 3203-3211

[6] Hossain, M. A., and Takka, H. S., (1996) Radiation effect on mixed convection along a vertical plate with uniform surface temperature, Heat and Mass Transfer/Waerme-und Stoffuebertragung, 31, 243-248

[7] Kishinami, K., Saito, H., and Suzuki, J. (1995) ) Combined forced and free laminar convective heat transfer from a vertical plate with coupling of discontinuous surface heating International Journal of Numerical Methods for Heat and Fluid Flow, 5, 839-851.

[8] Tewari, S. S., and Jaluria, Y. (1990) Mixed convection heat transfer from thermal sources mounted on horizontal and vertical surfaces, ASME Journal of Heat Transfer, 112, 975987. 